\title{
Agressividade e Raiva: Perfil de Presidiários
}

Aggressiveness and Anger: Prisoners' Profile

Elizelma

Ortencio Ferreira \&

Cláudio Garcia Capitão

Universidade

São Francisco

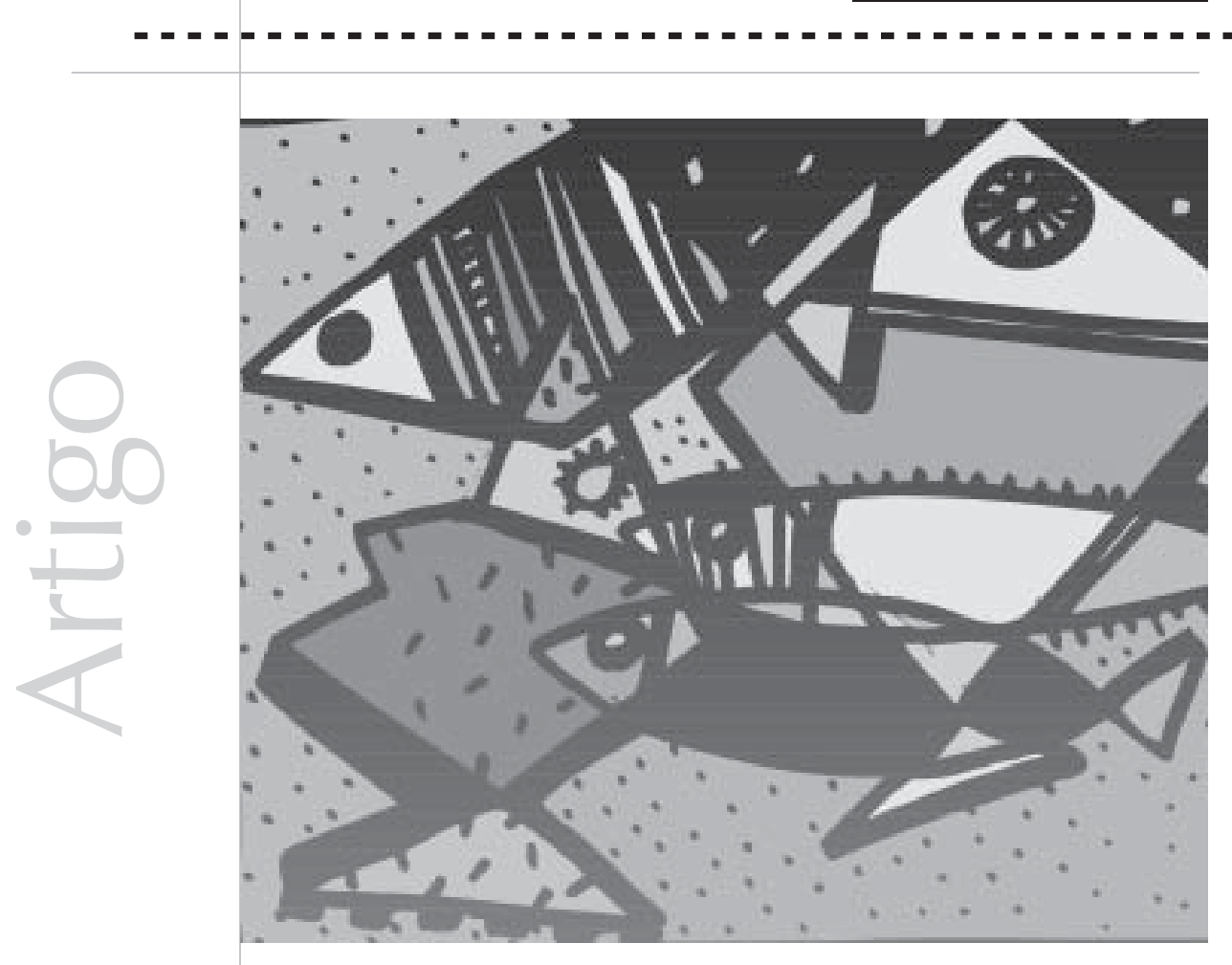




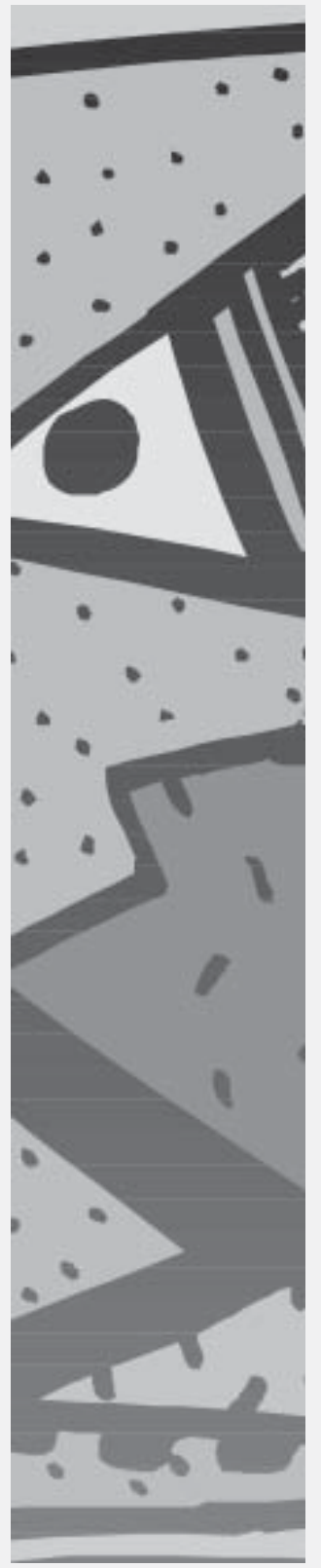

Resumo: Este trabalho verificou diferenças entre o tipo de delito (furto, roubo, seqüestro, homicídio, latrocínio e outros) e os construtos agressividade e raiva por meio do Teste de Frustração de Rosenzweig (PF) e do Inventário de Expressão e Raiva em Estado e Traço (STAXI), respectivamente. Aplicaram-se ambos os testes em cento e vinte e cinco presidiários de uma penitenciária de segurança máxima do interior de São Paulo. A análise de variância ANOVA indicou que o grupo de seqüestradores apresenta, no STAXI, uma instabilidade muito grande entre os fatores relativos à raiva, enquanto os que não praticaram seqüestro têm uma estabilidade aparentemente maior. A diferença significativa para o fator intrapunitivo, no PF, mostrou que os indivíduos que cometeram furto reprimem menos a agressividade em situações de frustração, quando comparados àqueles que não cometeram tal delito.

Palavras-chave: agressividade, avaliação psicológica, perfil de presidiários, raiva, testes psicológicos.

Abstract:The present work has checked differences between the kind of transgression (theft, robbery, kidnapping, homicide, holdup, among others) and aggressiveness and anger constructs through the Rosenzweig Frustration Test (PF) and the State-Trait Anger Expression Inventory (STAXI), respectively. Both tests have been applied to 125 prisoners in a country-side São Paulo top-security prison. The ANOVA variance analysis indicated that the kidnappers group presents, at STAXI, great instability within the factors related to anger, while the non-kidnappers are apparently more stable. The significant difference for the intrapunitive factor, in the PF, has shown that repression of aggressiveness is lesser for the individuals under frustration situations who committed theft than for the non-theft individuals. According to the results obtained, one will understand that the research has attained the established goals due to the differences found among groups, considering the several kinds of transgressions.

Key words: aggressiveness, psychological assessment, profile of prisoners, anger, psychological tests.

\section{Agressividade, agressão e raiva}

O termo agressividade é reconhecido como inato ao ser humano. A agressividade representa uma forma de proteção contra ameaças externas. Para Freud (1998), a agressividade é uma condição da fisiologia humana, que necessita de um estímulo ambiental para ocorrer.
Freud (1998) afirma, em Além do Princípio do Prazer, que todo organismo vivo é constituído por um conjunto pulsional, composto pela pulsão de vida (eros) e pela pulsão de morte (tânatos). A pulsão de vida diz respeito ao amor, ao afeto, à libido e às atitudes construtivas ou altruísticas, e tende não 
somente a preservar a vida como também a reproduzir outras. Já a pulsão de morte, ou destrutiva, atuante em todo ser vivo, luta para destruí-lo. Nenhuma dessas duas pulsões é mais essencial do que a outra, uma vez que elas estão entrelaçadas, mas seria possível dissociá-las e suas manifestações serem contrárias entre si bem como haver uma fusão para alcançar um objetivo.

Denomina-se masoquismo à parte da pulsão de morte que permanece no ego da pessoa e que proporciona a auto-agressão. Masoquismo e sadismo estão relacionados. Este último foi inicialmente considerado por Freud (1969b) um componente da pulsão sexual. O sadismo, sob essa visão, consiste no exercício da violência ou da força sobre outra pessoa, tomada como seu objeto. Após reformulações em sua teoria, Freud (1969a, 1998) passa a considerar o sadismo como muito mais autodestruidor do que a agressão voltada para o mundo exterior, fazendo da auto-agressão o próprio princípio da agressividade. A agressão, no homem, é um fenômeno secundário, um desvio da pulsão de morte para fora do eu, para o qual estava inicialmente dirigido. A noção de agressão manifesta, como relação de violência exercida sobre o outro, é modificada, e é então descrita como uma expressão externa da pulsão de morte que conta com o auxílio específico da musculatura. Referindo-se ao funcionamento externo da pulsão de morte, Freud (1997) postula que a agressão é o maior impedimento à civilização. Ele entende por civilização as experiências de grupo, raça, família, entre outros, que a humanidade experimenta. Esse processo de socialização é equivalente à pulsão de vida. No ser humano, a pulsão agressiva coloca-se em oposição aos objetivos mais elevados da civilização e ocasiona conflito entre as pessoas. A prevalência da pulsão agressiva sobre o processo de civilização resultará numa inclinação para a agressão, que poderá ser evidenciada no comportamento de pessoas com tal disposição. Para que isso ocorra, a pessoa não precisa estar acometida de alguma patologia psicológica específica. A agressão aparece como um fator que perturba os relacionamentos, o que faz com que a sociedade passe a despender maior energia na contenção dos comportamentos agressivos e a permanecer sob constante ameaça de desintegração.

Freud (1998), Storr (1970) e Winnicott (1999) descrevem que o agente inibitório primário da agressão é o superego, sendo este desenvolvido no processo de interação ambiental da criança com a família. Algumas crianças se desenvolvem de maneira a tornarem-se incapazes de controlar sua agressão quando adultas e a agir de acordo com seu próprio impulso hostil. Nesses adultos, a agressão ou é reprimida e voltada para o próprio ego ou é deserdada e atribuída aos outros, sendo expressa sob formas explosivas e infantis, o que os impede de integrarem suas agressões de modo positivo.

Maccoby e Jacklin (1978), Spielberger (1992) e Staub (1975) se referem à agressão como a ação de agredir, atacar veementemente o outro com finalidade destrutiva ou punitiva, ou seja, é uma forma de comportamento interpessoal. Além disso, no aspecto criminológico, a manifestação do comportamento agressivo visa a infringir os direitos do outro.

A hostilidade, embora envolva sentimentos de raiva, geralmente tem a conotação de um conjunto complexo de sentimentos agressivos e freqüentemente vingativos, enquanto a raiva é vista como um conceito mais elementar que a agressão e a hostilidade. Spielberger (1992) define a raiva como um estado emocional que abarca sentimentos que se diversificam desde o aborrecimento leve, ou a irritação, até a fúria, seguidos por uma estimulação do sistema nervoso autônomo. Diante dessa definição, entende-se que a raiva é uma condição necessária, mas não suficiente, para promover a manifestação de comportamentos agressivos. 
Rosenzweig $(1944,1948)$ se refere à agressão como apenas uma das respostas alternativas a uma situação de frustração. Por frustração, entendem-se todas as vezes que o organismo se depara com um obstáculo ou dificuldade, mais ou menos intransponível, no caminho que o conduz à satisfação de qualquer necessidade vital. Existem dois tipos de frustração: a frustração primária ou privação, que é caracterizada pela quantidade de tensão e insatisfação subjetiva, decorrente da ausência de uma situação final essencial à satisfação da necessidade ativa; a secundária é constituída pela presença de obstáculos ou dificuldades no caminho que conduz à satisfação de uma necessidade.

Uma formulação importante na teoria geral da frustração de Rosenzweig (1944) é o conceito de tolerância à frustração, que se define pela atitude de a pessoa suportar frustração sem perder sua adaptação psicológica, em outras palavras, sem recorrer a tipos de respostas inadequadas. Essa formulação abrange o fenômeno da adaptação em seu conjunto e implica também a existência de diferenças individuais nas situações de tolerância à frustração. Essas diferenças estão relacionadas com a gravidade da pressão e também com as características da personalidade da pessoa. A tendência para avaliar negativamente, para desconfiar ou suspeitar de outros pode influenciar na baixa tolerância à frustração.

Bion (1991) diz que a capacidade de tolerar frustrações é inata, sendo da mãe não só o importante papel de continente das angústias como também o de provedora das necessidades básicas ao bebê. Segundo essa teoria, a formação do pensamento tem como ponto de partida a frustração de algumas necessidades básicas que são impostas ao bebê. Nesse processo, o essencial é a menor ou maior capacidade de o bebê tolerar o ódio resultante dessas frustrações. Quando a capacidade para tolerar frustrações é suficiente, a experiência torna-se um elemento do pensamento e se desenvolve um aparelho para pensá-lo, e, ao contrário, se a capacidade para tolerar frustração for insuficiente, a experiência será internalizada como algo mau que deve ser evadido e expulso - o que é feito por meio de agitação motora na criança e no adulto, ou seja, de atuações.

Tratando-se de instrumentos psicológicos projetivos que avaliam a tolerância à frustração, o Teste de Frustração de Rosenzweig (PF, 1948) é um instrumento projetivo em que o sujeito é colocado diante de uma situação supostamente frustrante. A resposta é analisada e pode ser classificada na direção da agressão como extrapunitiva, intrapunitiva e impunitiva e no tipo de reação do sujeito, a saber: predominância do obstáculo, defesa do ego e persistência da necessidade. $\mathrm{O}$ Inventário de Expressão de Raiva em Estado e Traço (STAXI, 1992) oferece medidas concisas da experiência e expressão da raiva, representadas na forma de seis escalas, que são Raiva para Dentro, Raiva para Fora, Controle da Raiva, Expressão da Raiva, Estado da Raiva e Traço de Raiva, assim como duas subescalas: Temperamento Raivoso e Reação de Raiva.

Rosenzweig (1948) comparou delinqüentes e não delinqüentes com o objetivo de verificar a predominância de respostas nos dois grupos. A amostra foi composta de duzentos e cinqüenta delinqüentes e duzentos e cinqüenta não-delinqüentes. Ele observou uma predominância de respostas na categoria intrapunitiva para o grupo "não- delinqüentes", enquanto a categoria extrapunitiva predominou nas respostas do grupo "delinqüentes". Ele concluiu que uma resposta de agressão depende do jogo de um conjunto de fatores que se prendem à interpretação cognitiva da situação frustrante, com a sua intensidade, a força dos controles internos e externos, e, acima de tudo, com a tolerância à frustração. Rocha (1976) aplicou o PF em sessenta 
delinqüentes e sessenta não-delinqüentes do sexo masculino na cidade de Porto Alegre, de acordo com a delinqüência. $\mathrm{O}$ resultado desse estudo mostrou que os não-delinqüentes manifestam maior agressividade do que os delinqüentes. A delinqüência não estaria relacionada com o grau de agressividade do indivíduo, mas sim, com a impulsividade, a falta de controle sobre os impulsos, inclusive os agressivos. Assim, a agressividade é uma característica do comportamento delinqüente e também do não-delinqüente.

Cabe descrever que o delinqüente e a delinqüência são termos encontrados na legislação para denominar crime juvenil. Delinqüente e delinqüência também são considerados como sinônimos de infrator e criminalidade (Williams, 1955, citado por Feldman, 1979; Dias \& Andrade, 1997).

Megargee e Hokanson (1976) sugerem uma dinâmica de personalidade diferente para delinqüentes agressivos, que podem ser divididos em dois tipos distintos - o supercontrolado e o subcontrolado. O tipo de personalidade supercontrolado ocorre em pessoas extremamente inibidas. À medida que as respostas alternativas são bloqueadas, também é inibida a expressão de uma resposta agressiva, ocorrendo maior frustração e instigação. A instigação residual, isto é, a parte restante dos estímulos agressivos provocados pela frustração, pode permanecer ativa por longos períodos de tempo e aumentar com outras frustrações; esse mecanismo é o responsável por explosões paradoxais de violência observadas em indivíduos usualmente quietos e inofensivos. O tipo subcontrolado se refere às características de personalidade cujas inibições em relação ao comportamento agressivo são muito baixas. Devido ao baixo nível de inibições, a pessoa tende a ser diagnosticada como possuidora de uma personalidade sociopática, anti-social ou dissocial. Por isso, a dinâmica de personalidade assemelha-se à de muitas outras pessoas que têm dificuldades com a Justiça. Quanto às pessoas que cometeram homicídios ou agressão com arma mortal, algumas são do tipo cronicamente supercontrolado, e outras, do tipo agressivo subcontrolado.

Relacionados ainda ao tipo de personalidade de delinqüentes agressivos, existem fatores externos e internos que contribuem para sua formação. No que diz respeito aos fatores internos, Dewald (1972) se refere a criminosos que não manifestam sentimento de culpa, explicando que estes não internalizaram um conjunto de valores morais que pudessem utilizar. Tal fato ocorre principalmente quando as funções do superego permanecem exteriorizadas e não implicam conflito intrapsíquico. Os criminosos podem mostrar seus conflitos de distintas formas, ligadas a condutas anti-sociais (roubo, vício, etc), em vez de experimentá-los como estados subjetivos de conflito, acompanhados de malestar interno.

Quanto aos fatores externos, são vários os que colaboram para variações na formação de identidade de tais pessoas. São eles sociofamiliares, socioeconômicos ou socioambientais. Além disso, outras variáveis, como as migrações, as inadaptações sociais e as exigências culturais, influenciam na formação de identidade. Nesse contexto, a pessoa pode assumir tanto uma identidade dentro dos padrões esperados quanto outra - reprovável ou negativa para a sociedade, como a do delinqüente (Mussen et al.,1995).

Adolescentes influenciados pela situação socioeconômica como um todo estão mais inclinados, devido a dificuldades financeiras, a ficar deprimidos, a usar drogas ou a tornaremse delinqüentes. Além disso, os veículos de comunicação (televisão, rádio) incentivam os crimes ou instigam a sua reincidência (Bee, 1997).

Singer (1975) destaca a violência apresentada na televisão, representações ficcionais de 
assalto e de morte. A apresentação de cenas de atividade criminosa e de violência pode não só instruir as pessoas a respeito de meios inteligentes ou eficientes para a execução de vários crimes como levar os observadores de atividades agressivas numa tela à imitação direta do comportamento observado, seja por imaturidade, seja por sugestionalidade.

Para se verificar o perfil de presidiários, utilizouse, neste estudo, uma técnica denominada por Tabachinick e Fidell (1996) Análise de Perfis de Medidas Repetidas. Tal técnica consiste no tratamento de dados e análise de variância multivariada. Essa análise procura responder se o perfil de médias em um conjunto de medidas (parte intra-sujeitos do delineamento) é diferente para grupos distintos. O efeito da variável desempenha um papel fundamental do ponto de vista estatístico, pois sua inclusão no modelo possibilita reduzir a variância de erro, uma vez que, sendo significativo, explicaria uma parcela da variância, removendo-a do montante de erro e implementando o poder estatístico do teste. A análise de medidas repetidas preserva a independência dos grupos, mesmo quando um mesmo sujeito pertencer a vários grupos simultaneamente, ou seja, mesmo se o respondente cometer vários tipos de delito, a independência dos grupos será mantida. Além disso, com tal análise, procura-se compensar o problema de inflar o erro tipo I, que advém ao se fazer uma série de provas $t$ na comparação das médias dos grupos em várias medidas dependentes (Hair, Anderson, Tatham \& Black, 1995).

Encontraram-se poucos estudos na literatura psicológica que tratam de perfis de presidiários utilizando o teste PF e o STAXI. Verona e Carbonell (2000) investigaram o conceito hostilidade supercontrolada para explicar o crime violento entre cento e oitenta e seis presidiárias americanas, que foram classificadas como não-violentas (NV), um pouco violentas $(\mathrm{OV})$, ou criminosas bastante violentas (RV).
Foram utilizados o inventário de personalidade de multifásico de Minnesota ( $2^{\underline{a}}$ ed.) (MMPI 2) e o teste STAXI. Os resultados apontaram diferenças significativas entre os grupos OV e RV e pouco significativa entre as presidiárias com histórico criminal não-violento. Verificaram diferenças significativas na escala de hostilidade do MMPI-2, que efetivamente diferenciaram o grupo OV dos outros dois grupos, NV e RV. Evidenciou-se também, no grupo OV, maior tendência à agressão depois do grupo RV. O grupo RV apresentou, em sua maioria, expressão da Raiva para Fora. Esses dados destacam a importância do construto hostilidade bem como sua distinção, supercontrolada e pouco controlada, na análise de presidiárias.

Cabral e Stangenhaus (1992) analisaram características de sessenta e dois presidiários comparando-as com as características de cinqüenta pessoas de um grupo controle. Utilizaram como método uma anamnesequestionário, na qual constavam questões fechadas (sim ou não) e abertas. Foram encontradas, nos presidiários, características de personalidade relacionada a pouco controle da agressividade aliada a uma baixa tolerância à frustração, características essas que os autores descreveram como personalidade anti-social e borderline.

Guillaume e Proulx (2002) compararam características de personalidade de dezesseis criminosos violentos, descritos como borderline, com dezoito criminosos violentos descritos como narcisistas. Foi utilizado o instrumento Inventário Clínico Multiaxial Millon (Millon, 1983), versão francesa. Os resultados das análises mostraram que o grupo de criminosos borderline apresenta não só problemas relacionados ao uso de drogas e álcool como também emprega mais agressão física no curso de assalto, enquanto os criminosos narcisistas aparentemente possuem maior controle da agressividade. 
Quanto à escolaridade, dos cento e vinte e cinco

participantes, cento e quatorze não terminaramo primeiro grau, e apenas um sujeito, solteiro, apresenta ensino médio completo.
Corapçioglu e Erdogan (2004) investigaram o sentimento de raiva bem como a forma de se lidar com ela em prisioneiros com e sem reincidência criminal. Os prisioneiros responderam ao Inventário de Expressão de Raiva como Estado e Traço (STAXI). Os dados sociodemográficos foram coletados por meio de um questionário, caracterizando o motivo de aprisionamento, a sentença e a natureza do crime em que cada presidiário foi envolvido, sua história criminal, uso de álcool e outras substâncias. Dos quatrocentos e trinta e oito prisioneiros, trezentos e dois (68.9\%) responderam o STAXI. A reincidência de crimes foi observada em $37,4 \%$ da amostra. Os resultados apontaram que prisioneiros reincidentes apresentaram uma elevação nas respostas de Traço de Raiva, Raiva para Fora e Raiva para Dentro, quando comparados aos criminosos sem histórico de reincidência criminal. Os autores concluíram que, se os presidiários com histórico de reincidência criminal forem ajudados a identificar e a controlar a raiva, o risco de cometerem um novo crime poderá ser minimizado.

Souza (1990) examinou o comportamento agressivo na sua condição potencial hereditária e também em ação manifesta provocada pelo ambiente. No intuito de investigar o construto agressividade, utilizou os testes Desenho da Figura Humana (DFH), Psicodiagnóstico Miocinético (PMK) e o PF. O mesmo autor pretendia, ainda, construir uma escala de agressividade a partir dos resultados encontrados. Sua pesquisa constou de três grupos culturalmente diferenciados. O primeiro grupo foi composto de trinta menores infratoras, o segundo de vinte e cinco noviças de duas ordens religiosas, e o terceiro, de trinta estudantes universitárias do curso de Psicologia. A aplicação foi coletiva para os testes DFH e PF, e individual para o PMK. Dos resultados obtidos, apenas a variável extrapunitividade discriminou os grupos. Os resultados encontrados impossibilitaram a construção de uma escala de sinais identificadores de agressividade.
Pelos trabalhos citados, pode-se notar que traçar diferentes perfis para presidiários, de acordo com o tipo de delito cometido, poderia contribuir, em vários aspectos, num sistema prisional, e, portanto, ser de grande utilidade em tal contexto. Pretendeu-se, então, com este estudo, verificar a relação de dependência entre o tipo de delito [furto, roubo, seqüestro, homicídio, latrocínio e outros] com os construtos agressividade e raiva, lembrando que, em se tratando de testes psicológicos, construto corresponde ao conceito particular que orientou toda a construção do instrumento.

\section{Método}

Participantes

Foram participantes do estudo cento e vinte e cinco presidiários, do sexo masculino, estudantes do ensino fundamental e médio. A faixa etária dos participantes variou de dezenove anos a quarenta e seis anos [ $\mathrm{M}=$ vinte e nove anos e oito meses; DP = seis anos e quatro meses]. A maior concentração de faixa etária foi entre vinte e seis e trinta anos, e apenas um sujeito tinha mais de quarenta e cinco anos.

No que se refere à situação conjugal, uma parte dos participantes era amasiada $(n=53)$ situação que se caracteriza por estar partilhando um mesmo lar com outra pessoa, porém sem que isso seja oficializado nos termos da lei.

Quanto à escolaridade, dos cento e vinte e cinco participantes, cento e quatorze não terminaram o primeiro grau, e apenas um sujeito, solteiro, apresenta ensino médio completo. Dos cinqüenta e três sujeitos amasiados, cinqüenta possuem ensino fundamental incompleto, assim como, dos quarenta e oito participantes solteiros, quarenta e dois apresentam ensino fundamental incompleto. Vale salientar o baixo índice de escolaridade dos participantes do estudo. 
Instrumentos

Dois instrumentos foram utilizados: um foi o Teste de Frustração de Rosenzweig (PF) (Rosenzweig, 1944), que propõe explorar as reações do indivíduo frente a situações de frustração, tendo como fundamento a teoria geral da frustração. A edição para adultos é chamada The Rosenzweig P. F. Study, Form for Adults, datada de 1944 e revisada em 1948. Uma adaptação francesa foi realizada em 1951. O teste é composto por desenhos de caráter uniforme que lembram histórias em quadrinhos, como estímulos, a fim de favorecer a identificação por parte do indivíduo; as respostas dimensão e alcance do instrumento são limitadas. $\mathrm{O}$ instrumento compreende uma série de vinte e quatro desenhos, representando, cada um, dois personagens colocados em uma situação de frustração do tipo comum. A situação do desenho consiste em o personagem da esquerda pronunciar algumas palavras que descrevem a frustração do outro indivíduo ou a sua própria. A pessoa da direita tem, acima dela, um quadro vazio, destinado a receber suas palavras. Os traços e a mímica dos personagens no desenho foram sistematicamente negligenciados para favorecer a identificação de quem vai responder pelo personagem. O teste se destina a adultos e adolescentes (Rosenzweig, 1944).

De acordo com Rosenzweig (1944), as respostas são consideradas segundo a direção das reações agressivas (extrapunitiva, impunitiva e intrapunitiva) e pelo tipo de reação desenvolvida (predominância do obstáculo, defesa do ego e persistência da necessidade), resultando em nove combinações de fatores possíveis de cotação. Ao ser anotada uma determinada resposta, é necessário decidir se a agressão está expressa contra o ambiente (reação extrapunitiva), voltada contra o próprio indivíduo (intrapunitiviva) ou suprimida e encoberta (impunitiva). Deve-se, ao mesmo tempo, considerar se a resposta representa um bloqueio à altura da própria frustração (dominância do obstáculo), uma defesa contra ameaças do ego existentes na situação geralmente sob forma de atribuição da culpa (defesa do ego), ou um impulso em direção à solução do problema (persistência da necessidade).

O outro instrumento utilizado foi o Inventário de Expressão de Raiva como estado e traço (STAXI) (Spielberger, 1992), que fornece medidas concisas da experiência e expressão da raiva sob a forma de estado e traço. Spielberger (1992) propõe que a raiva varia em intensidade e flutua com o passar do tempo, como uma função da percepção de injustiça ou frustração resultante do impedimento do comportamento dirigido a um objetivo. Quanto ao Traço de Raiva, foi definido em termos de diferenças individuais na freqüência com que o Estado de Raiva era experienciado com o passar do tempo. Foi estabelecido como pressuposto que indivíduos com Traço de Raiva mais alto eram mais propensos a perceber uma vasta gama de situações como incitadoras de raiva (aborrecidas, irritantes, frustrantes) e a responder a tais situações com elevações no estado de raiva.

O teste é composto por quarenta e quatro itens, os quais formam seis escalas e duas subescalas. A primeira escala é denominada Estado de Raiva, composta por dez itens que medem a intensidade dos sentimentos de raiva num determinado momento. A escala Traço de Raiva é composta por dez itens que medem as diferenças individuais na disposição para vivenciar a raiva. Dessa escala, foram definidos dois conjuntos de quatro itens, dando origem a duas subescalas: Temperamento Raivoso, que mede a propensão geral para vivenciar e expressar a raiva sem provocação específica, e Reação de Raiva, que mede diferenças individuais na disposição para expressar a raiva quando criticado. A Raiva para Dentro é uma escala representada por oito itens que medem a freqüência com que os sentimentos de raiva 
são reprimidos. Já a Raiva para Fora é uma escala de expressão da raiva composta por oito itens que medem com que freqüência o indivíduo expressa a raiva em relação aos outros. Controle da Raiva é uma escala composta por oito itens que medem a freqüência com que o indivíduo tenta controlar a expressão da raiva. A última escala, Expressão da Raiva, é baseada nas vinte e quatro respostas das três escalas, Raiva para Dentro, Raiva para Fora e Controle da Raiva. Seu escore fornece um índice em que a raiva é expressa, não importando a direção (Spielberger, 1992).

Procedimento

O estudo foi submetido ao Comitê de Ética em Pesquisa da Universidade, protocolo no 433/03. O contato inicial com os sujeitos ocorreu por meio de entrevista coletiva, com o objetivo de estimular a aceitação do estudo, com explicações sobre o mesmo. Nessa oportunidade, foi entregue, para assinatura, o Termo de Consentimento Livre e Esclarecido. Foi destacado aos participantes que as informações obtidas seriam sigilosas. As entrevistas ocorreram no horário de aula e foram necessárias sete entrevistas. Cada entrevista durou aproximadamente trinta minutos.

Num segundo momento, procedeu-se à aplicação dos instrumentos, que foi coletiva, com subgrupos de aproximadamente vinte sujeitos, tendo sido aplicado primeiro o STAXI, em seguida, o PF, e, em cada dia, ocorreu apenas uma aplicação dos instrumentos, com duração de aproximadamente uma hora para cada.

\section{Resultados e discussão}

A seguir, são apresentadas as análises descritivas dos instrumentos. São descritas também as análises de variância ANOVA - mais especificamente, a prova denominada pela literatura de Análise de Perfis de Medidas Repetidas.

\section{Estatísticas descritivas para o STAXI}

Como já mencionado, o STAXI é um teste composto de quarenta e quatro itens (dispostos em seis escalas e duas subescalas) do tipo likert, com quatro possibilidades de resposta, pontuadas de um (para absolutamente não ou quase nunca) a quatro (para quase sempre ou muito). A pontuação do teste, portanto, podia variar de quarenta e quatro a cento e setenta e seis, com ponto médio igual a cento e dez. Verificou-se que o valor mínimo das pontuações foi de quarenta quatro, e o máximo de cento e trinta e oito, com uma média de 80,1 ( $\mathrm{DP}=12,9)$.

A Tabela 1 apresenta o número de sujeitos, mínimo, máximo, média e desvio padrão dos resultados do STAXI, encontrados na amostra de presidiários.

Tabela 1- Estatística descritiva das escalas do STAXI

\begin{tabular}{|l|c|c|c|c|c|}
\hline Escalas do Staxi & N & Mínimo & Máximo & Média & Desvio Padrão \\
\hline Traço de Raiva & 125 & 10 & 34 & 17,2 & 5,21 \\
\hline Estado de Raiva & 124 & 10 & 34 & 11,71 & 3,60 \\
\hline Temperamento & 125 & 4 & 14 & 6,42 & 2,32 \\
\hline Reação de Raiva & 125 & 4 & 15 & 7,86 & 2,77 \\
\hline Raiva para Dentro & 125 & 8 & 30 & 15,76 & 4,79 \\
\hline Raiva para Fora & 124 & 10 & 33 & 16,31 & 4,61 \\
\hline Controle de Raiva & 125 & 8 & 32 & 22,44 & 5,10 \\
\hline Expressão de Raiva & 124 & 6 & 55 & 25,67 & 9,47 \\
\hline
\end{tabular}


As pontuações das escalas Traço de Raiva e Estado de Raiva podiam variar de dez a quarenta, com o ponto médio igual a vinte e cinco. Observou-se que as médias das pontuações dos sujeitos da amostra nessas escalas foram inferiores ao seu ponto médio. Para as subescalas Temperamento de Raiva e Reação de Raiva, as pontuações podiam variar de quatro a dezesseis, com ponto médio igual a dez. Notou-se que as médias dos sujeitos nessas subescalas, da mesma forma, foram inferiores. As pontuações nas escalas Raiva para Dentro, Raiva para Fora e Controle de Raiva podiam variar de oito a trinta e dois, com o ponto médio igual a vinte. Percebeu-se que as médias dos sujeitos nas escalas Raiva para Dentro e Raiva para Fora também foram inferiores ao ponto médio. Ao contrário disso, a média dos sujeitos na escala Controle de Raiva foram superiores ao seu ponto médio. Por fim, as pontuações na escala Expressão de Raiva podiam variar de vinte e quatro a noventa e seis, com ponto médio igual a sessenta. Observou-se que os sujeitos obtiveram média inferior ao ponto médio da escala. Vale dizer ainda que a escala Expressão de Raiva obteve a maior média, seguida de Traço de Raiva. A escala Raiva para Fora apresentou média ligeiramente maior que Raiva para Dentro. Conforme o esperado, houve maior pontuação na escala Raiva para Fora, quando comparada com Raiva para Dentro.

\section{Estatísticas descritivas para o Teste de Frustração de Rosenzweig}

O teste PF, conforme já mencionado, é um instrumento projetivo que se constitui de vinte e quatro situações, para as quais o sujeito pode dar de uma a três respostas. Essas respostas são classificadas quanto à direção da agressão e tipo de reação. Neste estudo, obteve-se o máximo de duas respostas por situação. A Tabela 2 mostra o total de respostas de cento e vinte e quatro sujeitos, visto que um não respondeu o teste. Na primeira coluna, estão descritas as respostas bem como suas combinações obtidas no PF. Na segunda coluna, estão apresentadas as respostas em valores brutos, e, na última, a porcentagem.

Tabela 2 - Freqüência dos fatores (extrapunitivo, intrapunitivo, impunitivo e combinações) do PF $(n=124)$

\begin{tabular}{|l|c|c|}
\hline Fatores do PF & Respostas & Porcentagem (\%) \\
\hline Extrapunitivo & 1065 & 35,8 \\
\hline Intrapunitivo & 610 & 20,5 \\
\hline Impunitivo & 730 & 24,6 \\
\hline Extrapunitivo e intrapunitivo & 71 & 2,4 \\
\hline Extrapunitivo e impunitivo & 133 & 4,5 \\
\hline Intrapunitivo e impunitivo & 102 & 3,4 \\
\hline Extrapunitivo e extrapunitivo & 37 & 1,2 \\
\hline Intrapunitivo e intrapunitivo & 114 & 3,8 \\
\hline Impunitivo e impunitivo & 111 & 3,7 \\
\hline Total & 2973 & 100 \\
\hline
\end{tabular}

Notou-se que, do total de duas mil, novecentos e setenta e três respostas, mil e sessenta e cinco foram respostas extrapunitivas. Esse resultado demonstra forte tendência da amostra em atribuir a frustração a pessoas ou coisas externas, e, ao contrário, o menor número de respostas para o fator intrapunitivo indica que poucos sujeitos dirigem a agressão para si próprios, quando frustrados. Os resultados sugerem, ainda, que pessoas que atribuem a agressão ao outro ou ao ambiente reprimem pouco sua agressão, dirigem a culpa ao outro, assim como à situação frustrante, isso quando são 
comparados os resultados dos fatores extrapunitivo, intrapunitivo e impunitivo.

Esses resultados estão equiparados aos encontrados por Rosenzweig (1948), que observou uma predominância de respostas na categoria extrapunitiva em um grupo de "delinqüentes". De fato, uma resposta de agressão depende de um conjunto de fatores que se depreendem com a interpretação cognitiva da situação frustrante, com a sua intensidade, a força dos controles internos e externos, e, acima de tudo, com a tolerância à frustração. Nesse caso, a característica predominante da amostra em lidar com as situações de frustração denota uma reação ao dirigir a agressão ao outro, ou seja, por meio de atuações ou ações motoras, o que leva a pensar em uma baixa tolerância às frustrações (Bion, 1991).

\section{Análises de variância}

Para investigar diferenças entre sujeitos que praticaram distintos tipos de delitos em relação ao sentimento de raiva, foi efetuada a análise de perfis de medidas repetidas, que consiste em uma especificidade da análise de variância multivariada. Essa análise procura responder se o perfil de médias em um conjunto de medidas (parte intra-sujeitos do delineamento) é diferente para grupos distintos (Tabachinick \& Fidell, 1996).

Entende-se que os itens de um certo fator propõem afirmações de um tema específico que requerem do sujeito uma resposta que indique sua concordância com as afirmações. Desse modo, no fundo, o que se está medindo, ou seja, a variável dependente, é a concordância com as afirmações propostas, e os escores dos participantes nos oito fatores representam seu perfil de concordância em relação aos oito temas propostos. Assim, essa análise de perfil procura investigar até que ponto o perfil dos grupos de sujeitos definidos em função de uma variável qualquer são distintos.
Nesse caso, foram formados dois grupos, determinados em razão da presença ou ausência de determinado delito, nos quais foram comparados os oito fatores do STAXI. A análise empregada, portanto, foi a MANOVA $2 \times 8$, tendo como variáveis independentes o tipo de delito, e dependentes, os fatores mencionados. Empregando essa análise, procurou-se, prioritariamente, verificar até que ponto existem interações significativas entre os fatores referidos e o tipo de delito. Tais efeitos, ao serem significativos, indicam que os perfis de médias nos fatores do STAXI dependem do subgrupo que está sendo considerado.

O efeito da variável fatores do STAXI, embora não seja alvo de interesse teórico, desempenha um papel fundamental do ponto de vista estatístico, já que sua inclusão no modelo possibilita reduzir a variância de erro, uma vez que, sendo significativo, explicaria uma parcela da variância ao removê-la do montante de erro e implementar o poder do teste estatístico.

Outra razão pela qual se optou por essa análise reside no fato de que o mesmo respondente pode ter cometido mais de um tipo de delito. Assim, sem esse tratamento dos dados, a independência dos grupos pode ser violada, inviabilizando essa comparação da forma como se pretendeu. Além disso, procurou-se compensar o problema de inflar o erro tipo I, que advém ao se fazer uma série de provas $t$ na comparação das médias dos grupos em várias medidas dependentes (Hair, Anderson, Tatham \& Black, 1995).

Para realizar a análise de variância, foram transformados os resultados brutos em escorespadrão t. As notas t foram usadas, visto que são transformações lineares dos escores brutos, com média cinqüenta e com desvio padrão dez.

Os resultados dessa análise, comparando-se os grupos de indivíduos que cometeram 
seqüestro e aqueles que não praticaram tal delito, encontram-se na Tabela 3. Como pode ser observado, ao se considerar os oito fatores combinados, houve diferenças significativas entre os grupos com efeito de interação (seqüestro $x$ fatores, $\ddot{E}=0,88, p=0,05$ ), sendo que a associação foi de $3,5 \%$.

Tabela 3 - Resultados da ANOVA verificando o efeito do delito (seqüestro) e conteúdo dos itens (fatores) na concordância com os itens.

\begin{tabular}{|l|l|l|l|l|l|l|}
\hline $\begin{array}{l}\text { Fonte de variância } \\
\text { Entre grupos }\end{array}$ & $S Q$ & $g^{a}$ & $M Q$ & $F$ & $P$ & Eta $^{2}$ \\
\hline $\begin{array}{l}\text { Seqüestro } \\
\text { Erro }\end{array}$ & 1173,56 & 1 & 1173,56 & 4,78 & 0,031 & 0,038 \\
\hline Intra grupos & 29893,65 & 122 & 245,03 & & & \\
\hline Fatores & 1532,84 & 3,80 & 402,87 & 3,65 & 0,007 & 0,020 \\
\hline Fatores x seqüestro & 1850,81 & 3,80 & 486,44 & 4,41 & 0,002 & 0,035 \\
\hline Erro & 51158,13 & 464,18 & 110,21 & & & \\
\hline
\end{tabular}

a Valores corrigido pela fórmula Greenhouse-Geisser para compensar a violação do postulado da simetria composta (Howell, 1997).

O efeito da variância dos fatores demonstrou também ser significativo (2\%). O perfil dos escores médios dos sujeitos nos fatores para os dois grupos pode ser melhor visualizado na Figura 1. Pode-se verificar que o grupo que não seqüestra apresenta médias mais baixas nos fatores 1, 2, 3, 4, 6 e 8, (Estado de Raiva, Traço de Raiva, Temperamento de Raiva, Reação de Raiva, Raiva para Fora e Expressão de Raiva) enquanto, no fator 5 (Raiva para Dentro), são praticamente as mesmas, e, para o fator 7 (Controle de Raiva), o grupo de seqüestradores denotou menor média em relação àqueles que não cometeram tal delito. Nota-se, ainda, que o grupo de seqüestradores apresenta uma instabilidade muito grande entre os fatores relativos à raiva, enquanto os que não praticaram seqüestro têm uma estabilidade aparentemente maior. Esses dados classificam o grupo de seqüestro ao que Verona e Carbonell (2000) descreveram como criminosos bastante violentos. Com exceção das respostas de Raiva para Dentro, os resultados são equiparados aos encontrados por Corapçioglu e Erdogan (2004), no qual criminosos reincidentes apresentaram uma elevação de respostas em Traço de Raiva e Raiva para Fora.

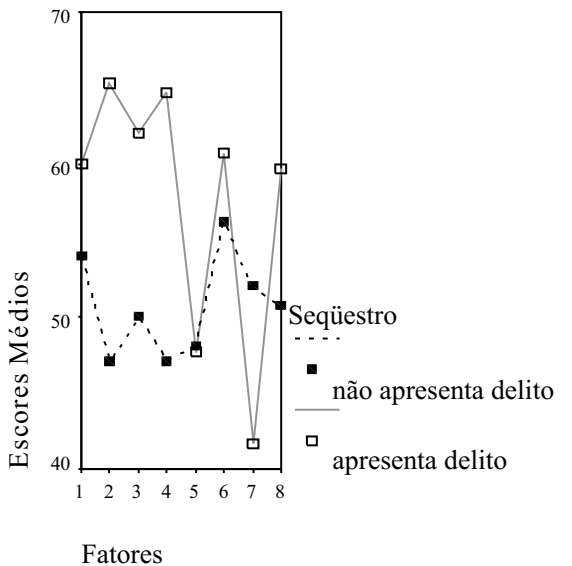

Figura 1. Escores médios dos oito fatores do STAXI em função da ausência e presença do delito seqüestro.

Diante desse resultado, realizaram-se análises univariadas para cada variável dos fatores, com vistas a investigar as diferenças em fatores específicos. Os resultados dessa análise indicaram diferenças significativas para os fatores Traço de Raiva, Temperamento de Raiva, Reação de Raiva e Controle de Raiva $(F=9,12, p=0,00 ; F=5,49, p=0,02 ; F=11,25$, $p=0,00 ; F=3,95, p=0,04$, respectivamente). 
Os fatores Raiva para Dentro, Raiva para Fora e Expressão de Raiva não demonstraram diferenças significativas, indicando que os seqüestradores e os que não cometem tal delito tendem a expressar a raiva da mesma forma. As diferenças significativas nos fatores Traço de Raiva, Temperamento de Raiva, Reação de Raiva e Controle de Raiva indicam que os seqüestradores experimentam e expressam mais os sentimentos de raiva com pouca ou sem nenhuma provocação, ou seja, tais indivíduos apresentam reações impulsivas. O fator Reação de Raiva obteve a maior diferença de média entre os grupos, salientando que os seqüestradores são mais sensíveis a críticas e afrontas e reagem de forma diferente quando se encontram nessas situações em relação àqueles que não praticaram tal delito.

É interessante dizer que tais sujeitos cometeram, além do delito seqüestro, todos os outros cinco, ou seja, em suas fichas criminais, apresentam condenações pelos seis tipos de delitos. O perfil do grupo de seqüestradores da amostra se assemelha ao tipo de personalidade subcontrolado, antisocial ou borderline descrito por Cabral e Stangenhaus, 1992; Guillaume e Proulx, 2002; Megargee e Hokanson, 1976. A literatura aponta, para esse perfil, fatores interiores - como a ausência de valores morais (Dewald, 1972) - e exteriores - como as inadaptações sociais, exigências culturais e ou situação socioeconômica (Bee, 1997; Mussen et al, 1995; Singer, 1975).

Foi empregada a análise MANOVA 2X3, tendo como variáveis independentes o tipo de delito, e dependentes, os fatores extrapunitivo, intrapunitivo e impunitivo. Nesse caso, também foram formados dois grupos, determinados em razão da presença ou ausência de determinado delito, nos quais foram comparados os três fatores do PF.

Verificou-se, então, até que ponto os fatores do PF diferenciavam os grupos de indivíduos que praticaram furto dos que não cometeram tal delito. Os resultados dessa análise, comparando-se os grupos de indivíduos que cometeram furto e aqueles que não cometeram tal delito, encontra-se na Tabela 4. Como pode ser observado, ao se considerar os três fatores combinados, houve diferenças significativas entre os grupos com efeito de interação (furto $x$ fatores, $\ddot{E}=0,95, p=0,05$ ), sendo a associação de $2 \%$.

Tabela 4 - Resultados da ANOVA verificando o efeito do delito (furto) e conteúdo dos itens (fatores) na concordância com os itens.

\begin{tabular}{|l|l|l|l|l|l|l|}
\hline & SQ & $G^{2}$ & $M Q$ & $F$ & $P$ & Eta $^{2}$ \\
\hline Entre grupos & & & & & & \\
\hline Furto & 89,98 & 1 & 89,98 & 2,48 & 0,11 & 0,02 \\
\hline Erro & 4423,57 & 122 & 36,25 & & & \\
\hline Intra grupos & & & & & & \\
\hline Fatores PF & 1286,15 & 1,61 & 794,22 & 5,54 & 0,00 & 0,04 \\
\hline Fatores PF x furto & 589,76 & 1,61 & 364,19 & 2,54 & 0,09 & 0,02 \\
\hline Erro & 28280,84 & 244 & 115,90 & & & \\
\hline
\end{tabular}

a Valores corrigido pela fórmula Greenhouse-Geisser para compensar a violação do postulado da simetria composta (Howell, 1997).

O efeito da variância dos fatores demonstrou também ser significativo (4\%). O perfil dos escores médios dos sujeitos nos fatores para os dois grupos pode ser mais bem visualizado na Figura 2 . Pode-se verificar que o grupo que furta apresenta média mais alta no fator 1 (extrapunitividade), enquanto, nos fatores 2 e 3 (intrapunitividade e impunitividade), o grupo de furto denotou menor 
média em relação àqueles que não cometeram tal delito. Nota-se, ainda, que o grupo de furto apresenta uma instabilidade muito grande entre os fatores relativos à direção da agressão, enquanto os que não apresentaram furto têm uma estabilidade aparentemente maior. $\mathrm{O}$ grupo de delito furto apresenta fortes inclinações para dirigir a agressão ao outro ou ao ambiente, e muito pouco ao próprio self.

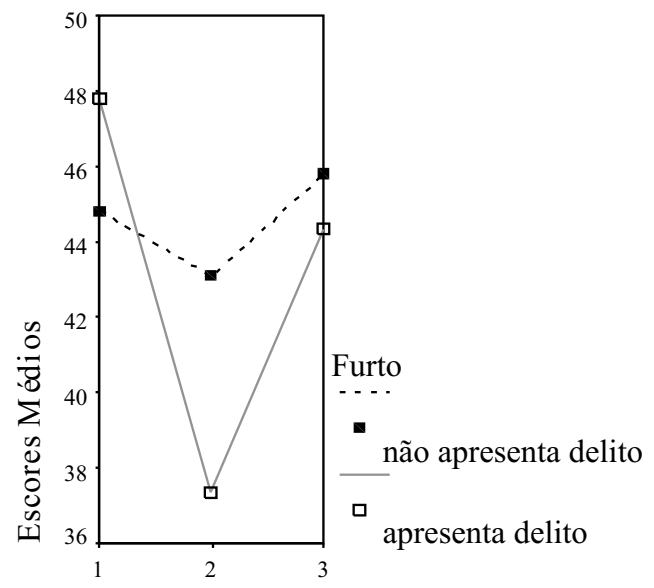

Fatores Direção da Agressão PF

Figura 2. Escores médios dos três fatores do PF em função da ausência e presença do delito furto.

Diante desse resultado, realizaram-se análises univariadas para cada variável dos fatores com vistas a investigar as diferenças em fatores específicos. O resultado dessa análise indicou diferença significativa para o fator intrapunitivo $(F=5,26, p=0,02)$. A diferença significativa no fator intrapunitivo indica que os indivíduos que cometeram furto reagem de forma diferente no que concerne a dirigir a agressão para si próprios nas situações de frustração. Tais indivíduos, quando frustrados, reprimem menos a agressão ao outro em relação àqueles que não praticaram tal delito. Esses resultados são diferentes dos encontrados em um outro estudo com grupos de diferentes populações, nos quais o fator que discriminou os grupos foi a extrapunitividade (Souza, 1990). De fato, a diferença significativa de média para o fator intrapunitividade sugere pouco controle da agressividade, aliada a uma baixa tolerância à frustração e à falta de contato com os sentimentos de culpa (Cabral \& Satangnhaus, 1992; Dewald, 1972).

\section{Conclusões}

Este estudo buscou traçar perfis para presidiários, quando considerado o tipo de delito cometido pela pessoa. Com respaldo nos resultados, algumas evidências foram encontradas para responder à indagação do objetivo proposto. As análises descritivas permitiram caracterizar a amostra, informando como os sujeitos lidam com seus sentimentos de raiva e suas reações frente a situações de frustração. Pode-se dizer, portanto, que a maioria dos sujeitos expressam mais seus sentimentos de raiva do que os reprimem, dirigem a raiva ao outro ou a objetos equivalentes; nas situações de frustração, tendem a agredir o outro bem como a atribuir a culpa ao outro. Isso significa dizer que a maior parte das pessoas da amostra apresenta algumas características do tipo borderline .

A análise de variância mostrou diferenças de médias significativas entre os indivíduos que apresentaram o delito seqüestro e aqueles que não cometeram tal delito, quando considerada a combinação dos oito fatores do STAXI. As diferenças de médias permitiram concluir que o grupo de seqüestradores apresenta uma instabilidade muito grande entre os fatores relativos à raiva, enquanto os que não apresentaram seqüestro têm uma estabilidade aparentemente maior. As análises univariadas indicaram diferenças significativas para os fatores Traço de Raiva, Temperamento de Raiva, Reação de Raiva e Controle de Raiva. Portanto, pode-se dizer que os seqüestradores experimentam e expressam mais os sentimentos de raiva com pouca ou sem nenhuma provocação, ou seja, tais indivíduos 
apresentam reações impulsivas. A maior diferença de médias entre grupos ocorreu para o fator Reação de Raiva, indicando que os seqüestradores são mais sensíveis a críticas e afrontas e reagem de forma diferente, quando se encontram nessas situações, em relação àqueles que não cometeram tal delito.

As comparações entre grupos, nos três fatores do PF, mostraram diferenças de médias significativas entre o grupo que cometeu o delito furto e aqueles que não o cometeram. Constatou-se que os indivíduos que furtaram tendem, em situações de frustração, a reagir dirigindo a agressão para o outro ou para objetos equivalentes, os representantes ou causadores da frustração. As análises univariadas mostraram que as diferenças significativas ocorreram por causa do fator intrapunitivo. Isso significa que o grupo de delito furto pouco reage em situação de frustração, dirigindo a agressão ao próprio self, em relação aos que não cometeram tal delito. Pode-se dizer, ainda, que o grupo de furto apresenta uma instabilidade muito grande entre os fatores relativos à direção da agressão, enquanto os que não praticaram furto têm uma estabilidade aparentemente maior.

Sugere-se o desenvolvimento de outras pesquisas sobre perfis de presidiários em relação ao tipo de delito cometido pela pessoa. Também outros estudos sistemáticos sobre perfis de presidiários que utilizarem o teste PF, em território nacional, contribuirão para elevar a confiabilidade nos seus resultados. Sugere-se, ainda, a comparação com perfis de presidiários com outras populações e com outros instrumentos. 
BEE, H. O Ciclo Vital. Trad. Regina Garcez. Porto Alegre: Artes Médicas, 1997

BEMARD, G. \& PROULX J. Caracteristiques du Passage a l'Acte de Criminels Violents. États-limites et Narcissiques. Canadian Journal of Criminology, 44 (1), p. 51, 2002.

BION, W. R. O Aprender com a Experiência. Rio de Janeiro: Imago, 1991.

CABRAL, M. A. A. \& STANGENHAUS, G. Algumas Características de Personalidade de Presidiários com as de um Grupo Controle sem Antecedentes Criminais. Jornal Brasileiro de Psiquiatria, 41 (1), pp. 8-31, 1992

CORAPÇIOGLU, A. \& ERDOGAN S. A Cross-section on Expression of Anger and Factors Associated with Criminal Recidivism in Prisoners with Prior Offences. Forensic Sci Int., 140 (2-3), pp. 167-74, 2004. DEWALD, A. Psicoterapia: um Enfoque Dinâmico. Barcelona: Toray, 1972.

DIAS, J. F. \& ANDRADE, M. C. Criminologia: o Homem Delinqüente e a Sociedade Criminógena. 2a ed. Coimbra: Coimbra, 1997. FELDMAN, M. P. Comportamento Criminoso. Rio de Janeiro: Zahar, 1979

FREUD, S. O Problema Econômico do Masoquismo. Obras Completas, vol. XIX. Rio de Janeiro: Imago, 1969a (originalmente publicado em 1924).

Três Ensaios sobre a Teoria de Sexualidade. Obras

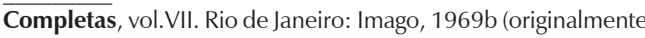
publicado em 1905).

O Mal-estar na Civilização. Obras Completas, vol. XXI. Rio de Janeiro: Imago (originalmente publicado em 1930 [1929].Título original: Das Unbehagen in der Kultur), 1997.

Além do Princípio do Prazer. Obras Completas, vol. XVIII. Rio de Janeiro: Imago (originalmente publicado em 1920. Título original: Jenseits des Lustprinzips), 1998.

GUILLAUME, B. \& PROULX, J. Caracteristiques du Passage a l'Acte de Criminels Violents. États-limites et Narcissiques. Canadian Journal of Criminology, 25 (44), p. 51, 2002.

HAIR, J.F., ANDERSON, R.E., THATAM, R.L. \& BLACK, W.C. Multivariate Data Analysis with Readings. New Jersey: Prenticehall International, 1995

HOWELL, D. C. Statistical Methods for Psychology. Boston: Duxbury, 1997.

MACCOBY, E. \& JACKLIN, C. N. The Psychology of Sex Differences Califórnia: Stanford, University Press, 1978.
MEGARGEE, E., I. \& HOKANSON, J. E. Tipos de Personalidade Subcontrolada e Supercontrolada em Agressão Anti-social Extrema. In: Megargee, E. I. \& Hokanson, E. J.(orgs.), A Dinâmica da Agressão: Análise de Indivíduos, Grupos e Nações. São Paulo: EPU, 1976 , pp.133-148.

MUSSEN, P. H., CONGER, 」. J., KAGAN, J. \& HUSTON, A. C. Desenvolvimento e Personalidade da Criança. $3^{\underline{a}}$ ed. São Paulo: Harbra, 1995

ROCHA, Z. O. Frustração e Agressividade em Adolescentes Delinqüentes e Não- delinqüentes. Tese de concurso para LivreDocência em Psicologia do Desenvolvimento, Pontifícia Universidade Católica do Rio Grande do Sul, Porto Alegre, 1976.

ROSENZWEIG, S. An Outline of Frustration Theory. In: J. Mc. V. Hunt (org.), Personality and Behavior Disorders, a Handbook Based on Experimental and Clinical Research, New York: The Ronald Press Company, 1994

Teste de Frustração: Manual de Psicologia Aplicada. Rio de Janeiro: CEPA, 1948.

SINGER, J. L. A Influência de Violência Representada na Televisão ou no Cinema sobre Comportamento Agressivo Manifesto. In: J. L. Singer (org.), O Controle da Agressão e da Violência. São Paulo: EPU, 1975.

SOUZA, I. O Comportamento Agressivo em Grupos Culturalmente Diferenciados. Tese de Doutorado. Programa de Estudos PósGraduados em Psicologia Clínica, Universidade de São Paulo, São Paulo, 1990

SPIELBERGER, C. D. Inventário de Expressão de Raiva como Estado e Traço (S.T.A.X.I.): Manual Técnico. Porto Alegre: Vetor, 1992.

STAUB, E. Aprendizagem e Desaprendizagem da Agressão. O Papel da Angústia, da Empatia, da Eficiência e dos Valores Sociais. In: J. L. Singer (org.), O Controle da Agressão e da Violência. Cap. 4. São Paulo: EPU, 1975, pp.120-154

STORR, A. A Agressão Humana. Rio de Janeiro: Zahar, 1970 (originalmente publicado em 1969).

TABACHINIK, B. G. \& FIDELL, I. S. Using Multivariate Statistics New York: Harper Collins, 1996.

VERONA, E.\& CARBONELL, J. L. Female Violence and Personality: Evidence for a Pattern of Overcontrolled Hostility Among One-Time Violent Female Offenders. Criminal Justice and Behavior, 27 (2), p. $176,2000$.

WINNICOTT, D. W. Privação e Delinqüência. São Paulo: Martins Fontes, 1999
Referências 